\title{
The use of some nanoemulsions based on aqueous propolis and lycopene extract in the skin's protective mechanisms against UVA radiation
}

\author{
Monica V Butnariu ${ }^{1 *+}$, Camelia V Giuchici ${ }^{2+}$
}

\begin{abstract}
Background: The use of natural products based on aqueous extract of propolis and lycopene in the skin's protective mechanisms against UVA radiation was evaluated by means of experimental acute inflammation on rat paw edema. The aim of the present study was to evaluate the harmlessness of propolis - lycopene system through evaluation of skin level changes and anti-inflammatory action. The regenerative and protective effect of the aqueous propolis and lycopene extract is based on its richness in biologically active substances such as: tocopherols, flavonoids, amino acids, polyunsaturated fatty acids, the chlorophyll pigment, all substances with strong antioxidant activity, that modify the oxidative stress, mainly by reducing the prooxidant processes and enhancing the antioxidant ones. These substances participate in the synthesis of prostaglandins and phospholipids components of cell membrane thus enhancing skin protection mechanisms.

Results: The experimental systems offered a sustained release of the drug, in vitro, for aim eight hours. The prepared formulations aim did not reveal a deteriorating effect on tissues. They proved a better therapeutic efficiency Compared to standard suspension, they provided a better therapeutic efficiency coupled with extended time interval of tested parameters (24 hours). Preliminary examination of tissues showed that the experimental formulations did not irritate. Local application of propolis and lycopene aqueous extract nanoemulsion has a high potential both regarding its efficiency (the analgesic effect) and therapeutic safety.

Conclusions: This study demonstrates that propolis and lycopene extract nanoemulsions, preparations contains active substances, can confer better therapeutic effects than those of the conventional formulations, based on local control-release of dozed form, for a longer period of time, which probably improve its efficiency and skin acceptance, meaning a better compliance. The information obtained in the present study suggests that administration of propolis and lycopene aqueous extract nanoemulsion is safe. The preparation can be useful for further preclinical studies lycopene embedded in aqueous propolis extract to be used in pharmaceuticals (targeted medical therapy).
\end{abstract}

\section{Background}

In recent years, it has been noticed that the incidence of skin cancer has increased alarmingly. Exposure to UV irradiation has instantaneous effects (erythema and pigmentation) and delayed effects (premature skin ageing

\footnotetext{
* Correspondence: monicabutnariu@yahoo.com

+ Contributed equally

'Exact Sciences Department, Banat's University of Agricultural Sciences and Veterinary Medicine from Timisoara, Calea Aradului no.119, 300645 Timisoara, Romania

Full list of author information is available at the end of the article
}

and different forms of cancer) [1]. UVB radiation has a stronger energy compared to UVA radiation and is absorbed directly by a series of cellular constituents, such as nucleic acids, proteins and urocanic acid. UVB radiation has also mutational effect [2]. UVA radiation penetrates easily through epidermis and acts on its basal proliferative layer and even on blood components of the dermis $[3,4]$. It acts indirectly on the cellular constituents, through oxidative mechanisms that forma reactive oxygen species $[5,6]$. Reactive oxygen species have a relative short lifespan, nevertheless are highly reactive

\section{Ciomed Central}


with the vast majority of cellular components: nucleic acids, proteins, lipids, polysaccharides. Frequently their action induces irreversible modifications $[7,8]$. UVA radiation acts upon biological environments through oxidative mechanisms, correlated with the formation of reactive oxygen species: singlet oxygen, hydroxyl radicals, superoxide anions, hydrogen peroxide [9]. Nucleic acids and proteins adsorb poorly radiation however but the initial event triggering biological effects is made up of absorption of UVA photons by different chromophores in the cellular environment such as: quinones, steroids, porphyrins, proteins with flavin coenzymes and heme group (cytochrome, peroxidase, catalase) [10]. Many cellular components are targed by reactive oxygen species generated by UVA irradiation $[11,12]$.

Hydroxyl radicals react with almost all cell molecules types: carbohydrates, phospholipids, nucleotides, organic acids and amino acids. On enzymes, the effect of reactive oxygen species results in catalytic capacity reduction, often determined by sulphhydryl oxidation and modification of amino groups by malonylation [13]. Organisms are protected against reactive oxygen species attack in several ways: cellular compartmentalization, protection afforded by antioxidant compounds and enzyme systems, their ability to develop adaptive responses inducible under oxidative stress conditions. Repair and turnover processes help to minimize these $[14,15]$. Under normal circumstances there is a balance between antioxidant systems and reactive oxygen generative systems. Lack of balance in favor of prooxidant systems causes the apparition of oxidative stress, with pathological implications [16]. Skin is the organ most exposed to solar radiation [17]. Skin presents a series of structures with a protective role, such as stratum corneum and melanin. Superficial corneum layer functions as optical barrier by reflection, scattering and absorption of incident radiation. Larger part of UVA radiation penetrates deeply into the skin, to dermis [18]. UVA radiation can be absorbed by different components of the blood, at the level of blood vessels. UVA radiation acts as inducer of enzymes responsible for polyamine synthesis. An additional mechanism of epidermis protection is to stimulate skin pigmentation with melanin [19]. The protection mechanisms are established and inducible protections at the skin level. Inducible defence mechanisms were not identified at epidermis [20], but was identified in dermis, where increased heme oxygenase, which are correlated with an increase in ferritin levels [21]. Pharmaceutical and cosmetics industries have launched a wide range of substances that act as filters capable of absorbing UV photons [22]. Photoprotection products are characterized by the protection factor. An accurate assessment of the effectiveness of photoprotection products should be based on their ability to inhibit the isomerisation reaction of urocanic acid and prevent accumulation of the protein [23]. "Quantum dot" nanostructures have been used (nanoparticles with quantum properties and ability to change size according to light emission). Another reason for the use of these products is their ability to "connect" many substances, thanks to a large surface area, and easy transport due to their small sizes (10 to 100 nanometers). These substances can also remain and accumulate preferentially at skin level, facilitated by surface drainage [24]. Currently, nanomedicine is seen not only as a possible and promising path to an early and effective treatment, but also a possible way to prevent certain types of diseases [25].

\section{Results}

\section{Characterization of lycopene extract}

Lycopene (Figure 1) belongs to the class of natural pigments, called carotenoids, with a role in protecting the body from the destructive effects of oxidants. Lycopene neutralizes the negative effects of free radicals. Furthermore, recent studies have shown that lycopene has a significant potential to counter free radicals in comparison with $\beta$-Carotene. Validation was confirmed by application of standard techniques lycopene determination. Aqueous extract of propolis has a high concentration of polyphenols and is standardized in polyphenol carboxylic acids (caffeic acid), responsible, among other active substances, for its healing and anti-inflammatory action upon tegument affected by dandruff and seborrheic dermatitis. Thus, the antimicrobial and antiinflammatory action of lycopene is enhanced and regeneration of skin affected by fungal and/or microbial infections is stimulated. The product formulation also considered physiological aspects of the skin, resulting in a product with low allergenic potential and high degreasing capacity. Because of the nanoemulsion pharmaceutical form, it has several advantages over other topical products with similar action. Thus, in contact with skin it quickly releases active substances due to its good adherence to skin and close contact it has a high therapeutic efficiency, easy administration low allergenic potential, good local tolerance and an increased viscosity, allowing the required concentration in bioactive compounds. Figure 2 clearly shows the absorption spectrum of the extracted lycopene solution. The absorption spectrum very closely coincided with the three peaks characteristic of trans-lycopene $(\lambda=446,472,505 \mathrm{~nm})$.

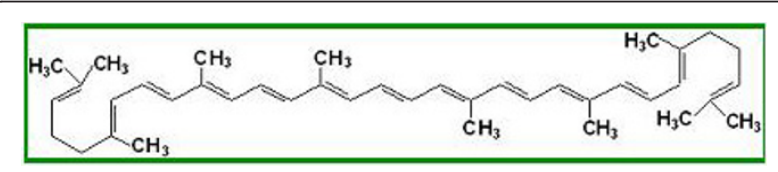

Figure 1 Molecule of lycopene (chemical structure). 


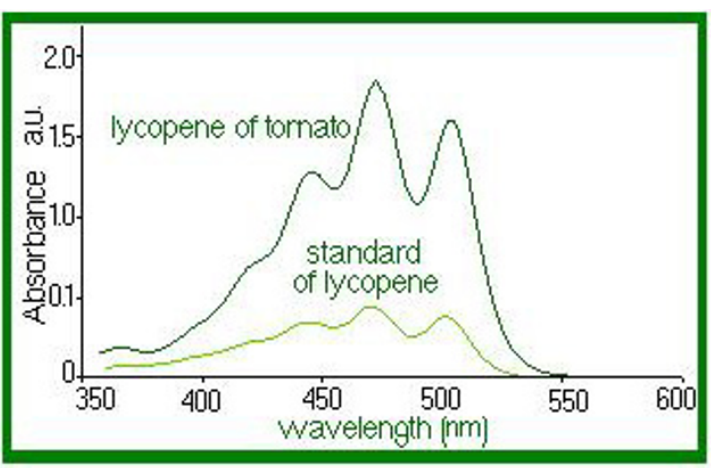

Figure 2 UV-VIS spectrum of lycopene extracted from tomatoes and of standard of lycopene

Any analytical method (bio analytical, in particular), in order to be validated, must demonstrate first that it is specified in relation to existing endogenous substances in the biological matrix, to metabolism products and reagents used in the sample preparation. For that, the specificity of this method was verified using six different sources of blank solutions. We aimed to see if there was any endogenous interference at the retention times of the experimental analytes. The linearity of the method was verified by the method of smallest squares, on the 0-3.0 $\mathrm{mg} / \mathrm{L}$ lycopene domain, using internal standard calibration as calibration model. Lycopene area and standard area ratio were calculated for seven levels of concentration in the selected domain and used for calibration curves. For each calibration point we examined the distribution, the relative percentage deviation of recalculated concentration from calibration curve equation. The calibration model was considered correct if residuals were within boundaries of $\pm 20 \%$ at lower limit and $\pm 15 \%$ at other concentrations and did not have a trend of increase or decrease along with concentration. Correlation was considered linear at a value of the determination coefficient greater than 0.99 , as seen in Figure 3. Accuracy, expressed as relative percentage

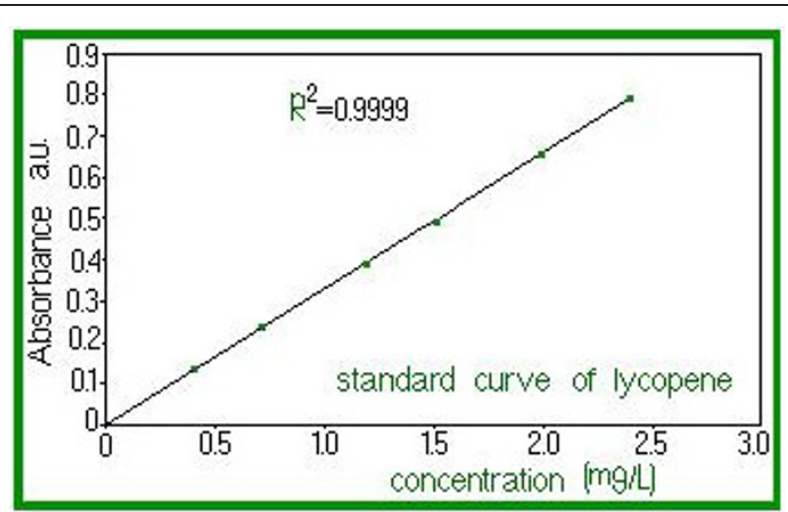

Figure 3 The calibration curve of lycopene standard. deviation of measured concentration in relation to the a obtained concentration, and precision, expressed as standard relative percentage deviation or coefficient of variation $\mathrm{CV} \%$, were determined at three concentration levels. Both, precision and accuracy were determined on the same day, based on five measurements on five different samples at each concentration, and accuracy and precision on different days based on the analysis on different days of five standard samples at each of the three levels of tested concentration. The lowest limit of quantification was considered the lowest concentration on the calibration line with an accuracy and precision within $\pm 20 \%$. Retrieval was assessed at four concentrations, including the lower limit of quantification, comparing the response obtained after application of UV radiation with that obtained with a standard solution of the same concentration in water and similarly processed as biological samples.

\section{FTIR analysis}

All FTIR analysis is considered technically "non-destructive" therefore further analysis can be performed. Composition analysis by FTIR spectroscopy (Fourier Transform Infrared) allows quantitative estimates and the study of links nature that appear during the nanoemulsions process. Following FTIR spectra analysis, no significant differences were apparent between the products. As shown in Figure 4, differences were found in FTIR spectra in the region 900-500 $\mathrm{nm}$ regarding experimental conditions and the resulting products. IR spectra highlight the presence of $-\mathrm{CH}_{2}$ - groups illustrated by the characteristic bands at $1450 \mathrm{~cm}^{-1}$ and $1460 \mathrm{~cm}^{-1}$ respectively. The nanoemulsion ester group causes the appearance of characteristic frequency bands at $1700 \mathrm{~cm}^{-1}(-\mathrm{C}=\mathrm{O}$ stretching $)$ given by a larger amount of propolis and lycopene. Increase in propolis content (the $30 \%$ option) determines the appearance of new frequency bands characteristic of the carbonyl group (1900-1600 $\mathrm{cm}^{-1}-\mathrm{C}=\mathrm{O}$ stretching). Growth leads (in propolis) to the disappearance of intense bands at $750-1280 \mathrm{~cm}^{-1}$, assigned to ring vibrations: $1235-1280$ $\mathrm{cm}^{-1}, 810-905 \mathrm{~cm}^{-1}$ and $805-875 \mathrm{~cm}^{-1}$ and can be attributed to characteristic methyl bands shielding or to the dissolution of certain groups during the process of obtaining the nanoemulsion. In the case of the bands group in the range of $1150-1250 \mathrm{~cm}^{-1}$, characteristic of ester groups (-C-O stretching), an increase in the intensity of the bands is observed, which is reflected in the decrease of its transmittance from $96 \%$ to $56 \%$. This is also explained by the increasing of the quantity of propolis from $27 \% \mathrm{v} / \mathrm{v}$ to $35 \% \mathrm{v} / \mathrm{v}$ in the nanoemulsion. High lycopene content of $35 \%$ has the effect of increased intensity of certain bands at $1450 \mathrm{~cm}^{-1}\left(-\mathrm{CH}_{3}\right.$ and $\mathrm{CH}_{2}$ $=$ strain) reflected in the decrease of the transmittance 


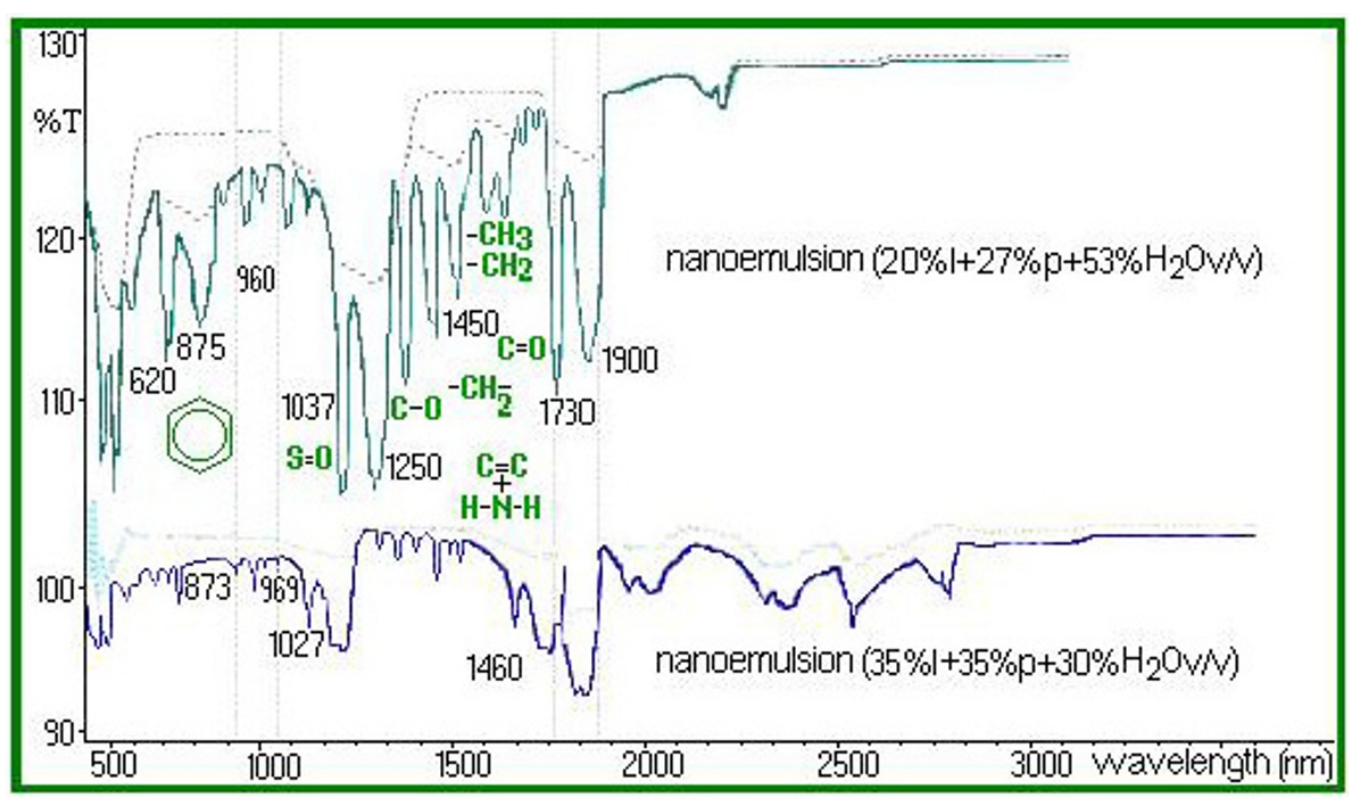

Figure 4 IR spectrum of nanoemulsions in $\mathrm{KBr}$ disc, obtained from experimental analysis

from $92 \%$ to $70.846 \%$. An intensity increase was observed at $1730 \mathrm{~cm}^{-1}(-\mathrm{C}=\mathrm{O}$ stretching) a characteristic of unsaturated esters. This growth is highlighted by the decrease of transmittance from $97.95 \%$ to $47.126 \%$ and is explained by $35 \%$ propolis content. The intensity significant increase of nanoemulsion bands characteristic is attributed to the increase of distance interactions between atoms and molecules, through altered angles between the links. In the case of experimental formulated nanoemulsions, for second formulation spectral bands intensity was reduced, which is consistent with the reported kinetic data (Table 1). Table 1 shows correlation

Table 1 Data correlation coefficients regarding the release of active constituents of propolis lycopene systems

\begin{tabular}{llllll}
\hline Sample & "n" & $\mathrm{R}$ & \multicolumn{2}{l}{ Higuchi Model } & \multicolumn{2}{l}{ Zero-order kinetics } \\
\cline { 3 - 5 } \cline { 3 - 5 } & & $\mathrm{k}\left(\% \mathrm{~h}^{-1 / 2}\right)$ & $\mathrm{R}$ & $\mathrm{k}\left(\% \mathrm{~h}^{-1}\right)$ & $\mathrm{R}$ \\
\hline
\end{tabular}

formulation with $20 \%$ lycopene, $27 \%$ propolis, $53 \%$ water vol./vol (nanoemulsion 1)

\begin{tabular}{|c|c|c|c|c|c|c|}
\hline Newly prepared & & & 4.45 & 0.997 & 0.62 & 0.994 \\
\hline After one week & 0.80 & 0.971 & 3.18 & 0.998 & 0.70 & 0.998 \\
\hline After two weeks & & & 4.21 & 0.982 & 0.78 & 0.998 \\
\hline After three weeks & & & 4.16 & 0.987 & 0.77 & 0.999 \\
\hline
\end{tabular}

formulation with 35\% lycopene, 35\% propolis, 30\% water vol./vol (nanoemulsion 2)

\begin{tabular}{|c|c|c|c|c|c|}
\hline Newly prepared & & 3.47 & 0.983 & 0.71 & 0.998 \\
\hline After one week & $0.98 \quad 0.980$ & 3.87 & 0.996 & 0.67 & 0.995 \\
\hline After two weeks & & 3.68 & 0.999 & 0.62 & 0.999 \\
\hline After three weeks & & 3.48 & 0.989 & 0.68 & 0.990 \\
\hline
\end{tabular}

coefficients of data regarding the release of formulated nanoemulsions, obtained from the Higuchi model, zero order kinetic and release exponent values (n) obtained from the equation $\mathrm{Mt} / \mathrm{Mo}=\mathrm{ktn}$ regarding the prepared nanoemulsions based on propolis lycopene $(n=3)$. During these experiments no changes were observed in the organoleptic properties of experimental formulations and $\mathrm{pH}$ value of the two nanoemulsions remained within the limits of $\pm 0.3 \mathrm{pH}$ units. No significant changes were noticed in terms of particle size $(\mathrm{p}<0.05)$.

\section{The properties of the two experimental formulations}

Micrometric properties of the two experimental formulations are shown in Table 2. This experiment highlighted the improved performances of the se emulsions without side effects and adverse reactions by replacing synthetic chemicals with natural products. It has been documented, that some UV radiation absorbers can be partially degraded therefore causing skin alterations while exposed

Table 2 Micrometric properties of the two formulations tested

\begin{tabular}{llll}
\hline No. & Micrometric property & $\begin{array}{l}\text { Nanoemulsion } \\
\mathbf{1}\end{array}$ & $\begin{array}{l}\text { Nanoemulsion } \\
\mathbf{2}\end{array}$ \\
\hline 1 & Response angle & $35.60 \pm 1.33$ & $51.94 \pm 1.68$ \\
\hline 2 & $\begin{array}{l}\text { Density of the nanoemulsion } \\
\text { (merged) }\end{array}$ & $0.38 \pm 0.03$ & $0.41 \pm 0.02$ \\
\hline 3 & Density of the nanoemulsion & $0.53 \pm 0.07$ & $0.42 \pm 0.02$ \\
\hline 4 & \% Porosity & $42 \pm 1.3$ & $68 \pm 2.4$ \\
\hline & $\begin{array}{l}\text { Each value represents the average ( } \pm \text { SD) of three independent } \\
\text { determinations. }\end{array}$ \\
\hline
\end{tabular}


to UV influencing the effectiveness of sunscreen protection. For information on UV absorbers, the nanoemulsions SPF in vitro parameters were investigated. UVA radiation, the UVA/UVB ratio and in vitro SPF were measured using the Diffey and Robson method. The efficiency of these products is measured by a coefficient, index or protective factor, noted SPF (sun protection factor) or PI (protection index), which is the ratio of the minimum dose of solar radiation that causes lowest skin redness, after and before skin application of these preparations.

\section{The higher the SPF values, the more efficient the photoprotection}

This experiment was conducted to determine the photoprotection capacity of natural substances in nanoemulsions. In both nanoemulsions we also introduced a UVR-absorber (Saliform), accepted by European standards, to observe its influence on the analyzed samples. In Table 3 presents the absorbance's of two nanoemulsions measured by UVA, UVA/UVB ratio and SPF. The obtained data show that most absorbance in the UV domain in the relative parameter 5 is present in nanoemulsion 2+ absorber-UVR (Saliform) 1:1 (v/v). Regarding UVA/UVB ratio with the relative parameter 0.82 , most absorbance is found in the same nanoemulsion and in the case of SPF with absolute parameter 10.9, in nanoemulsion 2. As shown by these results, highest absorbance parameters may be assigned to nanoemulsion 2. Experimental formulations showed a pseudoplastic rheology, under the influence of shear stress (Figure 5). The viscosity is directly dependent on the formulations content of propolis. Microscopic observations of the experimental nanoemulsions confirmed formation of spherical particles, as shown in Figure 5. Differences in droplet size of these formulations were not statistically significant (droplet size was found to be $45 \mu \mathrm{m}$ ). Nanoemulsions were kept for three weeks at $4^{\circ} \mathrm{C}$ in order to provide a stable formulation for local application. Nanoemulsion stability is shown in Figure 6, 7 and 8 . This study suggests that the nanoemulsions made of aqueous extract of propolis and lycopene and prepared with active substances may confer better

Table 3 UVA radiation, the UVA/UVB ratio and nanoemulsion SPF with and without UVR-absorber

\begin{tabular}{lllll}
\hline No. & Samples & UVA & UVA/UVB & SPF \\
\hline 1 & $\begin{array}{l}\text { Nanoemulsion 1+absorber-UVR } \\
(\text { Saliform) 1:1 }(\mathrm{V} / \mathrm{V})\end{array}$ & 4.0 & 0.71 & 5.9 \\
\hline 2 & $\begin{array}{l}\text { Nanoemulsion 2 +absorber-UVR } \\
\text { (Saliform) 1:1 (V/v) }\end{array}$ & 5 & 0.82 & 6.9 \\
\hline 3 & Nanoemulsion 1 & 3.1 & 0.24 & 9.1 \\
\hline 4 & Nanoemulsion 2 & 3.2 & 0.815 & 10.9 \\
\hline
\end{tabular}

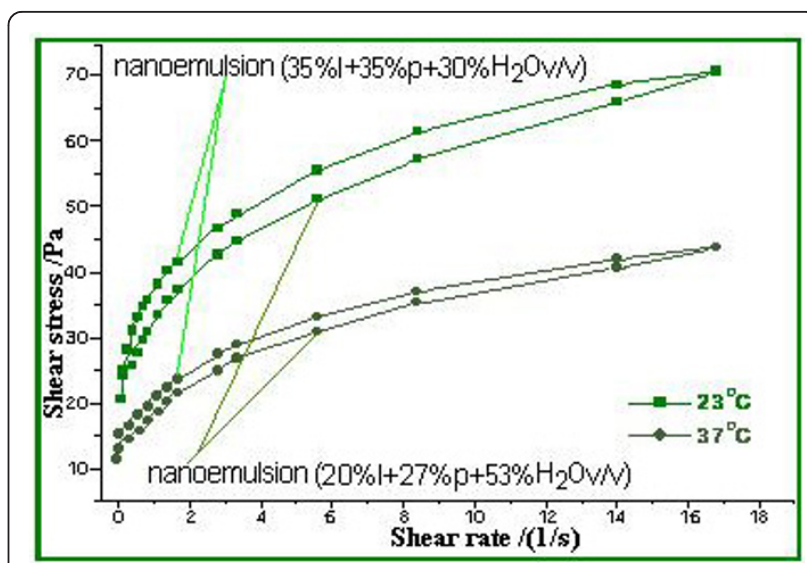

Figure 5 Dependence between the absorbance parameters of the two formulations.

therapeutic effects than conventional formulations, as a result of dose controlled local release longer period of time, which could lead to a greater efficiency and to a greater acceptance by the skin (i.e. better compliance). These results are supported by presented data in Table 4. Collagenase (inactive form of pre-collagenase, activated by trypsin) is an enzyme that cleaves the peptide bonds of fibrillar collagen types I and III. Experimental results showed that both nanoemulsions induced a reduction in collagenase activity. The intensity of antiinflammatory effect varies with time interval covered by the assessment of therapeutic response according to data in Table 4. The activity of propolis and lycopene nanoemulsions (Table 5) was emphasized by measuring the induced inflammation. Produced inflammation decreased by $75 \%$ for nanoemulsion 1 and $100 \%$ for nanoemulsion 2. The maximal inflammation reduction effect occurred after 8 hours from the initial application. Preliminary tissue examination showed that these formulations did not produce irritation. Local application of the experimental nanoemulsion (propolis and lycopene) has great potential, both in terms of efficacy

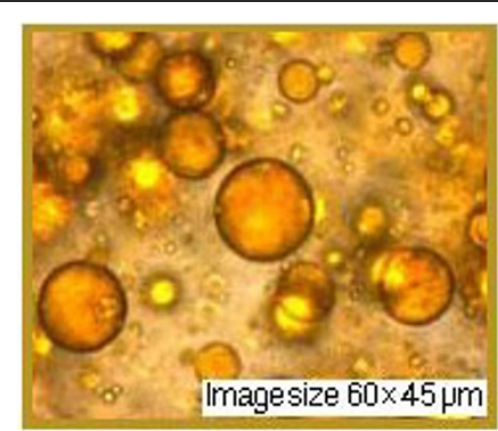

Figure 6 Nanoemulsion 2 layer (aqueous extract of propolis and lycopene) after one week. 


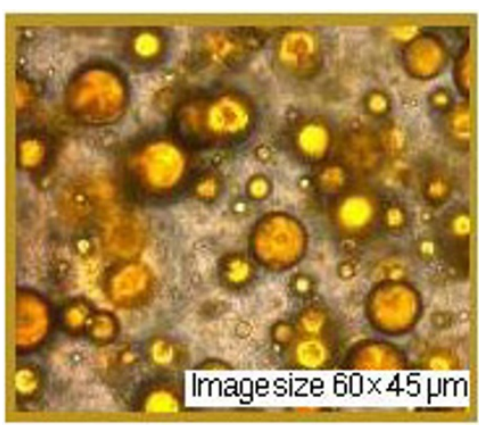

Figure 7 Nanoemulsion 2 layer (aqueous extract of propolis and lycopene) after two week

(analgesia) and therapeutic safety. Nanoemulsions have proved a better therapeutic efficacy compared to standard suspension, was observed improving monitored parameters for a longer period of time (24 hours). These systems can be seen as a viable alternative to conventional creams, due to their ability to improve residence time and thereby, bioavailability.

\section{Discussion}

Emulsions are a mixture of molecules in a combination of two liquids that keep their properties unaltered. This feature has been used in the delivery of poorly soluble drugs [26]. Nanoemulsions have a greater capacity for micellar solubilisation compared to simple solutions and offer advantages in thermodynamic stability to unstable dispersions (suspensions), as can be produced with less energy input and have a greater shelf life [27]. The nanoemulsions are systems with droplet sizes of approximately $45 \mu \mathrm{m}$, having surfactant ratios of $47 / 53$ and respectively 70/30 of aqueous extract of propolislycopene. UVA absorbance with relative parameter 5 is manifested by nanoemulsion 2 +absorber-UVR (Saliform) $1: 1(\mathrm{v} / \mathrm{v})$, in the case of the UVA/UVB ratio with relative parameter 0.82 by the same nanoemulsion and in the case of SPF with absolute parameter 10.9 by the

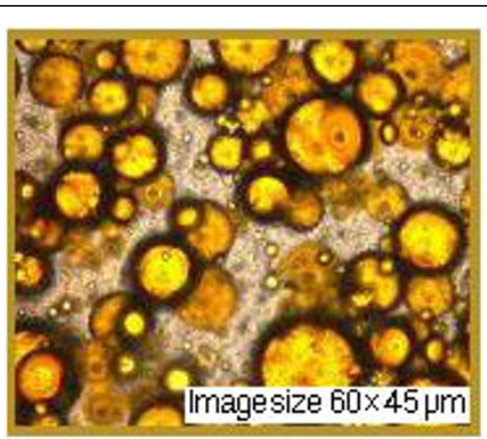

Figure 8 Nanoemulsion 2 layer (aqueous extract of propolis and lycopene) after three weeks.
Table 4 Enzymatic activity of collagenase in the presence of nanoemulsions

\begin{tabular}{llll}
\hline Substance & $\begin{array}{l}\text { Concentration } \\
(\boldsymbol{\mu g} / \mathrm{ml})\end{array}$ & $\begin{array}{l}\text { Enzymatic activity } \\
(\text { Units } / \mathbf{m g} \text { of } \\
\text { protein) }\end{array}$ & $\begin{array}{l}\% \\
\text { Inhibition }\end{array}$ \\
\hline Nanoemulsion 1 & 40 & $1.205 \pm 0.001$ & 26.81 \\
\hline Nanoemulsion 2 & 40 & $1.033 \pm 0.003$ & 37.14 \\
\hline $\begin{array}{l}\text { Without } \\
\text { nanoemulsion }\end{array}$ & - & $1.648 \pm 0.007$ & - \\
\hline \multicolumn{4}{r}{ Reaction conditions: $\mathrm{T}=25^{\circ} \mathrm{C}, \mathrm{pH} 7.5, \lambda=345 \mathrm{~nm}, \mathrm{t}=5 \mathrm{~min}}$. \\
\hline
\end{tabular}

nanoemulsion 2. Highest absorbance parameters can be assigned to nanoemulsion 2. Prepared formulations showed a pseudo-plastic rheology, under the influence of shear stress. It appears that viscosity is directly dependent on the propolis content of the formulation. Lycopene is insoluble in water; it can be dissolved only in organic solvents and oils [28-30]. Researchers have correlated the antioxidant function of lycopene (ability to protect cells and other body structures caused by oxidative damage) with the protection of DNA (our genetic material) inside the white blood cells [31].

White blood cells (WBC) are mediators of inflammation and the immune response. Unlike other food phytonutrients, whose effects have only been studied in animals, lycopene from tomatoes has been repeatedly studied in humans, where research has shown additional protection against many types of diseases $[32,33]$.

\section{Conclusions}

The experimental nanoemulsions in a high kinetic stability, and reduction in collagenase activity by $37.14 \%$ for a $70 / 30$ surfactant ratio and respectively $26.81 \%$ for a $47 / 53$ ratio. These nanoemulsions provided a sustained drug release in vitro for a period of 8 hours. Lycopene antioxidant as a nanoemulsion component beside its moisturizer characteristic improves the ability of the skin to defend against sunlight.

\section{Methods}

Aqueous extract of propolis

Aqueous extract of propolis was obtained by refluxing $100 \mathrm{~g}$ of propolis powder and $250 \mathrm{ml}$ of double distilled water. It was concentrated in a water bath then filtered resulting in $1.5 \mathrm{~cm}^{3}$ of extract with $95 \%$ of dry substance.

\section{Determination of lycopene}

Lycopene was obtained from ripe tomatoes (Lycopersicon esculentum) by solvent extraction. Samples were homogenized in a laboratory homogenizer. $5 \mathrm{ml} 0.05 \%$ BHT in acetone, $5 \mathrm{ml}$ of ethanol and $10 \mathrm{ml}$ of hexane were added to $0.6 \mathrm{~g}$ homogenated sample. The supplemented homogenate was kept on ice and stirred with a magnetic stirrer for 15 minutes. Then $3 \mathrm{ml}$ of deionized 
Table 5 Activity of aqueous extract of propolis and lycopene assessed on induced mouse paw edema

\begin{tabular}{|c|c|c|c|c|c|c|c|c|}
\hline \multirow[t]{2}{*}{ Compound } & \multicolumn{4}{|c|}{ Mean \pm SE difference in right and left paw volumes (ml) } & \multicolumn{4}{|c|}{ Reduction of edema (\%) } \\
\hline & $4 \mathrm{~h}$ & $6 \mathrm{~h}$ & $8 \mathrm{~h}$ & $24 \mathrm{~h}$ & $4 \mathrm{~h}$ & $6 \mathrm{~h}$ & $8 \mathrm{~h}$ & $24 \mathrm{~h}$ \\
\hline Control & $0.147 \pm 0.02$ & $0.186 \pm 0.11$ & $0.246 \pm 0.03$ & $0.165 \pm 0.01$ & - & - & - & - \\
\hline Regular sunscreen & $0.039 \pm 0.03$ & $0.026 \pm 0.10$ & $0.020 \pm 0.14$ & $0.015 \pm 0.004$ & 69 & 67 & 72 & 73 \\
\hline Nanoemulsion 1 & $0.019 \pm 0.03$ & $0.014 \pm 0.01$ & $0.011 \pm 0.02$ & $0.007 \pm 0.005$ & 97 & 85 & 78 & 75 \\
\hline Nanoemulsion 2 & $0.013 \pm 0.04$ & $0.008 \pm 0.02$ & $0.003 \pm 0.02$ & $0.001 \pm 0.00$ & 99 & 99 & 99 & 100 \\
\hline
\end{tabular}

water were added and samples were mixed for additional 5 minutes. Samples were then left at room temperature for 5 minutes to allow phase separation. The absorption of the hexane layer (upper layer) was measured in a $1 \mathrm{~cm}$ quartz cuvette at a wavelength of 503 $\mathrm{nm}$, against hexane as blank. Lycopene was measured quantitatively by UV-VIS spectrophotometer T60U, PG Instruments Limited, UV WIN $^{\circledR}$ version 5.05; detection was performed at $503 \mathrm{~nm}$ and calculated using the following formula:

Absorbance at $503 \mathrm{~nm}\left(\mathrm{~A}_{503}\right)=$

$\varepsilon\left(\mathrm{M}^{-1} \cdot \mathrm{cm}^{-1}\right) \cdot \mathrm{b}(\mathrm{cm})$

[Lycopene concentration (M)]

The measuring conditions were: scan speed $90 \mathrm{~nm} /$ min and an interval of $1 \mathrm{~nm}$. After extraction, was hexane evaporated to dryness in a vacuum evaporator, under a nitrogen stream [34]. All substances were purchased from Sigma Chemical.

\section{Preparation of nanoemulsions}

Nanoemulsions were prepared by adding lycopene to aqueous solution of propolis $(50 \mathrm{mg}$ propolis in $10 \mathrm{ml}$. W.), using a magnetic stirrer at $\sim 2000 \mathrm{rpm}$. The mixture was introduced for in an ultrasonic bath at $20 \mathrm{kHz} 20$ minutes. The nanoparticles that are formed have a lycopene-propolis loaded shape. After ultrasonic treatment the solution is brought at room temperature $\left(22^{\circ} \mathrm{C}\right)$.

The excess organic solvent in excess was evaporated using a rotary evaporator and samples were kept for further analysis by lyophilisation. Independent of preparation temperature, samples were kept at $25^{\circ} \mathrm{C}$ [35].

\section{Fourier transforms infrared spectrometry (FTIR)}

For spectral characterization (FTIR spectrometry), samples were prepared as follows: compounds obtained after heat treatment were mixed at a temperature of $1300^{\circ} \mathrm{C}$ with potassium bromide powder, previously dried for 24 hours at a temperature of $120^{\circ} \mathrm{C}$, at a mass ratio of 0.04:1. After a vigorous mix to obtain uniformisation, pills with a thickness of $0.5-0.75 \mathrm{~mm}$ and $13 \mathrm{~mm}$ in diameter at a pressure of $0.3 \mathrm{GPa}$ in normal atmosphere were prepared. The pills were analyzed using the JASCO 660 PLUS spectrophotometer, which recorded the IR absorption spectra in the area $4000 \mathrm{~cm}^{-1} 100$ $400 \mathrm{~cm}^{-1}$. For in vitro characterization of the experimental nanoemulsions, permeability studies and rheological measurements were carried out [36].

\section{Permeability studies}

Membrane permeability of the experimental nanoemulsions was investigated by filling the donor compartment of a diffusion cell with a $2 \mathrm{~g}$ test mixture. All other experimental conditions identical to those described for permeability studies of solid systems [37].

\section{Viscosity measurement}

Apparent viscosity of the experimental nanoemulsions was determined using a viscometer Brookfield Rheostress DV-III + Rheometer. Measurements were performed 3 times at $25^{\circ} \mathrm{C}$ using SC4 spindle. To determine the influence of shear stress applied to the microstructure of the prepared nanoemulsions, measurements were made at a rotation speed of 1 and 10 rpm.

Apparent viscosity of the controlled product (2\% HPMC dispersion in water), were examined under similar conditions [38].

\section{Enzyme activity measurements}

Enzyme activity is determined by a continuous spectrophotometric method, using as substrate 2-L-leucylglycyl furanacryloyl-L-prolyl-L-alanine (FALGPA, a specific collagenase substrate), as it is preferentially hydrolyzed much faster than other synthetic substrates.

Measurement of the substrate absorbance decrease was done at $345 \mathrm{~nm}$.

\section{Pharmacological evaluation of formulations}

Identification and quantification are done according to the methods described in the European Directorate for the Quality of Medicines [39].

\section{Animal testing}

Preparation: adult, young, healthy animals of the species of guinea pigs, breed albino were used. The animals were acclimatized to laboratory conditions for at least five days before test. Animals were divided randomly into treatment and control groups before test. Their skin was cleaned by clipping, shaving or, if possible, by chemical depilation without excoriation (cleaning 
method is based on the test method used). Animals have been weighed before and after test.

\section{Experimental procedure}

Superficial skin burns were induced using a UV radiation lamp.

\section{Testing the anti-inflammatory action}

Assessment of anti-inflammatory action was achieved by evaluating the inhibition of rat paw edema induced by a $2 \%$ solution of carrageenan.

The percentage inhibition of edema was calculated using the following equation:

Inhibition $(\%)=$

Mean paw diameter (control) - Mean paw diameter (treated) Mean paw diameter (control)

The edema inhibition rate of each group was calculated as follows:

Inhibition $(\%)=$

$\frac{\text { Mean number of writhing (control)-Mean of writhing (test) }}{\text { Mean number of writhing (control) }} \cdot 100$

Monitoring and staging: approximately 21 hours after the patch removal, hair is cleared off the surface exposed to challenge concentration. After 3 hours (about 30 hours after the challenge patch application) skin reactions were observed and recorded. After an additional time of 24 hours (54 hours) skin reactions were observed and recorded again. "Blind" reading is recommended for tested and control animals. All skin reactions and any unusual results, including systemic reactions caused by induction and challenge procedures were observed and recorded in accordance with the Magnusson/Kligman staging. If any of the reactions are difficult to interpret, other procedures can be taken into account, for instance histopathological examination or measurements of the skin fold.

Staging Magnusson/Kligman scale for assessing the post-challenge responses: $0=$ no visible change, $1=$ erythema or discrete form of spot, 2 = moderate and confluent erythema, 3 = intense erythema and swelling [40]

\section{Determination of in vitro sun protection factor (SPF)}

Determination of SPF (sun protection factor) was performed using a spectrophotometer, equipped with an integrating sphere, with appropriate software and a TRANSPOR 3 TM support, with a composition similar to that of natural skin, on which the amount of $2 \mathrm{mg} /$ $\mathrm{cm}^{2}$ of nanoemulsion was applied [40].

\section{Statistical analysis}

Values were expressed as mean \pm S.D. Statistical significance was evaluated by Students- „t" test at $5 \%$ level of significance $(\mathrm{p}<0.05)$.

\section{Acknowledgements}

The authors would like to thank the European regional development fund (ERDF) to finance project "Environment-Biochemical Cooperation for prognosis of natural water and soil pollution in the Hungarian and Romanian cross-border region to Shun Catastrophe" acronym "R \& D SZTE, BAÁE, no. HURO/0801/038".

\section{Author details}

'Exact Sciences Department, Banat's University of Agricultural Sciences and Veterinary Medicine from Timisoara, Calea Aradului no.119, 300645 Timisoara, Romania. ${ }^{2}$ Inspectorate for quality of seed and planting materials,

Delamarina Victor Vlad no. 3, 300077 Timisoara, Romania.

\section{Authors' contributions}

CG participated in the design of the study and performed the statistical analysis. MB conceived of the study, and participated in its design and coordination. All authors read and approved the final manuscript.

\section{Competing interests}

The authors declare that they have no competing interests. The opinions expressed in this article are those of the authors and do not necessarily represent any agency determination or policy.

Received: 23 November 2010 Accepted: 4 February 2011

Published: 4 February 2011

\section{References}

1. Kumar A, Bagewadi A, Keluskar V: Efficacy of lycopene in the management of oral submucous fibrosis. Oral Surg Oral Med Oral Pathol Oral Radiol Endod 2007, 103:207-213.

2. Applegate LA, Frenk E: Cellular defense mechanisms of the skin against oxidant stress and in particular UVA radiation. Eur.J.Dermatol 1995, 5:97-103.

3. Peak JG, Pilas B, Dudek EJ, Peak MJ: DNA breaks caused bz monochromatic $365 \mathrm{~nm}$ ultraviolet-A-radiation and their repair in human epithelioid and xeroderma pigmentosum cell. Photochem. Photobiol 1991, 54:197-203.

4. Dean RT, Fu S, Stocker R, Davies MJ: Biochemistry and pathology of radical-mediated protein oxidation. Biochem.J 1997, 324:1-18.

5. Shore RE: Radiation-induced skin cancer in humans. Med.Pediatr.Oncol 2001, 36:549-554.

6. Chandra RV, Prabhuji ML, Roopa DA: Efficacy of lycopene in the treatment of gingivitis: a randomised, placebo-controlled clinical trial. Oral Health Prev Dent 2007, 5:327-336.

7. Shao A, Hathcock JN: Risk assessment for the carotenoids lutein and lycopene. Regul Toxicol Pharmacol 2006, 45:289-298.

8. Sesso HD, Buring JE, Norkus EP: Plasma lycopene, other carotenoids, and retinol and the risk of cardiovascular disease in men. Am J Clin Nutr 2005, 81:990-997.

9. Halliday GM, Bestak R, Yuen KS, Cavanagh LL: Barnetson R.S. UVA-induced immunosuppression. Mutat.Res 1998, 422:139-45.

10. Khachik F, Carvalho L, Bernstein PS: Chemistry, distribution, and metabolism of tomato carotenoids and their impact on human health. Exp Biol Med 2002, 227:845-51.

11. Balasubramanian D: Ultraviolet radiation and cataract. J.Ocul Pharmacol Ther 2000, 16:285-297.

12. Hasegawa T, Kaneko F, Niwa Y: Changes in lipid peroxide levels and activity of reactive oxygen scavenging enzymes in skin, serum and liver following UVB irradiation in mice. Life Sci 1992, 50:1893-1903.

13. Chapple ILC: Reactive oxygen species and antioxidants in inflammatory diseases. J.Clin.Paradontol 1997, 24:287-296.

14. Kuusilehto A: Transmission of UVA radiation through epithelium of oral mucosa and skin in rat and man. Photodermatol.Photoimmunol.Photomed 2000, 16:189-191.

15. Cole $C$ : Sunscreen protection in the ultraviolet $A$ region: how to measure the effectiveness. Photodermatol.Photoimmunol.Photomed 2001, 17:2-10.

16. Morliere P, Moysan A, Tirache I: Action spectrum for UV-induced lipid peroxidation in cultured human skin fibroblasts. Free Rad.Biol.Med 1995, 19:365-371. 
17. Cunningham ML, Johnson JS, Giovanazzi SM, Peak MJ: Photosenzitized production of superoxide anion by monochromatic $(290-405 \mathrm{~nm})$ ultraviolet irradiation of NADH and NADPH coenzyms. Photochem. Photobiol 1985, 42:125-128

18. Peak MJ, Peak JG, Carnes BA: Induction of direct and indirect singlestrand breaks in human cell DNA by far-and near-ultraviolet radiations: Action spectrum and mechanisms. Photochem.Photobiol 1987, 45:381-387.

19. Stoker R: Induction of heme oxygenase as a defence against oxidative stress. Free Rad.Res.Comms 1990, 9:101-112.

20. Wang SQ, Setlow R, Berwick M, Polsky D, Marghoob AA, Kopf AW, Bart RS: Ultraviolet A and melanoma: a review. J.Am.Acad.Dermatol 2001, 44:837-846.

21. Dudek EJ, Peak JG, Roth RM, Peak MJ: Isolation of V79 fibroblast cell lines containing elevated metallothionein levels that have increased resistance to the cytotoxic effects of ultraviolet-A radiation. Photochem. Photobiol 1993, 58:836-840

22. Zigman S, McDaniel T, Schultz JB, Reddan J, Meydani M: Damage to cultured lens epithelial cells of squirrels and rabbit by UV-A (99.9\%) plus UV-B $(0.1 \%)$ radiation and alpha tocopherol protection. Mol.Cell Biochem 1995, 143:35-46.

23. European Directorate for the Quality of Medicines (EDQM), Council of Europe. Strasbourg, Cedex 1, France; 52005.

24. Goel RK, Singh A, Mahajan MP, Kulkarni SK: Evaluation of anti inflammatory and anti hyperalgesic activity of some novel monocyclic $\beta$-lactam compounds in rats. Indian J. Pharm. Sci 2004, 66:87-91.

25. Loftsson T, Masson M: Cyclodextrin in topical drug formulations: theory and practice. Int. J. Pharm 2001, 225:15-30.

26. Roco Mihail C: Nanotechnology: convergence with modern biology and medicine. CurrentOpinioninBiotechnology 2003, 14:337-346.

27. Blonska M, Bronikowska J, Pretsz G, Czuba ZP, Scheller S, Krol W: Effects of ethanol extract of propolis (EEP) and flavones on inducible gene expression in J774a, 1 makrophages. J. Ethnopharmacol 2004, 91:25-30.

28. Borrelli F, Maffia P, Pinto L, lanaro A, Russo A, Capasso F, Lalenti A: Phytochemical compounds involved in the antiinflammatory effectof propolis extract. Fitoterapia 2002, 73:353-363.

29. Denli M, Cankaya S, Silici S, Okan F, Uluocak AN: Effect-of dietary addition of Turkish propolis on the growth performance, carcass characteristics and serum variables of quail (Coturnix Coturnix Japanica). J. Anim. Sci 2005, 18:5.

30. Basuny MA, Mostafa MD, Azouz A: Supplementation of polyunsaturated oils with lycopene as natural antioxidant and antipolymerization during heating process. Minia J. Agric. Res. Develop 2006, 26(3):449-469.

31. Chasse GA, Mak ML, Deretey E: An ab initio computational study on selected lycopene isomers. J. Mol. Struc. (Theochem) 2001, 571:27-37.

32. Riso P, Visioli F, Grande S, Guarnieri S, Gardana C, Simonetti P: Effect of a tomato-based drink on markers of inflammation, immunomodulation and oxidative stress. J. Agric. Food Chem 2006, 54:2563-2566.

33. Omoni AO, Aluko RE: The anticarcinogenic and anti-atherogenic effects of lycopene: a review. Food Sci. Technol 2005, 16:344-350.

34. Kaur D, Ali Abas Wani Oberoi DPS, Sogi DS: Effect of extraction conditions on lycopene extractions from tomato processing waste skin using response surface methodology. Food Chem 2008, 108:711-718.

35. Kaur D, Wani AA, Sogi DS, Shivhare US: Sorption isotherms and drying characteristics of tomato skin isolated from tomato pomace. Drying Technol 2006, 24:1-6

36. Loftsson T, Masson M: The effects of water-soluble polymers on cyclodextrins and cyclodextrins solubilisation of the drugs. J. Drug Del. Sci. Tech 2004, 14:3-20.

37. $\mathrm{WHO}$, Regional Office for Europe, Largely preventable chronic diseases cause 86\% of deaths in Europe: 53 WHO European Member States map a strategy to curb the epidemic. Press Release EURO/05/06, Copenhagen; 2006.

38. European Technology Platform on NanoMedicine. Nanotechnology for Health-Vision Paper and Basis for a Strategic Research Agenda for NanoMedicine 2005.

39. European Medical Research Councils (EMRC): Nanomedicine, an ESFEuropean Medical Research Councils (EMRC) Forward Lookreport; 2005.

40. Singh Mritunjai, Singh Shinjini, Prasada S, Gambhir IS: Nanotechnology in medicine and antibacterial effect of silver nanoparticles. DigestJournal of Nanomaterials and Biostructures 2008, 3:115-122.

\section{doi:10.1186/1477-3155-9-3}

Cite this article as: Butnariu and Giuchici: The use of some nanoemulsions based on aqueous propolis and lycopene extract in the skin's protective mechanisms against UVA radiation. Journal of Nanobiotechnology 2011 9:3.

\section{Submit your next manuscript to BioMed Central and take full advantage of:}

- Convenient online submission

- Thorough peer review

- No space constraints or color figure charges

- Immediate publication on acceptance

- Inclusion in PubMed, CAS, Scopus and Google Scholar

- Research which is freely available for redistribution

Submit your manuscript at www.biomedcentral.com/submit
Biomed Central 